\title{
Nanocrystalline Diamond Films Deformation Observed During Sliding Tests against $\mathrm{Si}_{3} \mathrm{~N}_{4}$ Balls as a Possible Cause for Ripple Formation on Wear Scars Surface
}

\author{
Andrei BOGATOV ${ }^{1 *}$, Mart VILJUS ${ }^{2}$, Taavi RAADIK ${ }^{3}$, Thomas HANTSCHEL $^{4}$, \\ Vitali PODGURSKY ${ }^{1}$
}

${ }^{1}$ Tallinn University of Technology, Department of Materials Engineering, Ehitajate tee 5, 19086 Tallinn, Estonia

${ }^{2}$ Tallinn University of Technology, Center of Materials Research, Ehitajate tee 5, 19086 Tallinn, Estonia

${ }^{3}$ Tallinn University of Technology, Department of Materials Science, Ehitajate tee 5, 19086 Tallinn, Estonia

${ }^{4}$ Imec, Kapeldreef 75, B-3001 Leuven, Belgium

crossref http://dx.doi.org/10.5755/j01.ms.21.3.7232

\section{Received 02 June 2014; accepted 24 July 2014}

The study investigates wear performance of nanocrystalline diamond (NCD) films under reciprocating sliding conditions. The NCD films were grown by hot-filament chemical vapor deposition (HFCVD) method on (100) oriented Si wafers. The surface morphology was characterized by atomic force microscopy (AFM), scanning electron microscopy (SEM) and mechanical profilometry. The study focuses on the understanding of mechanisms resulting in NCD films deformation and formation of ripple patterns on the wear scars surface observed during reciprocal sliding tests. Plastic deformation of the Si wafer due to NCD film deposition and high local contact pressure and temperature during sliding lead to structural changes on the $\mathrm{Si}(100) / \mathrm{NCD}$ film interface, thus causing the NCD film to deform and the characteristic ripple patterns to develop on the wear scars surface.

Keywords: diamond films deformation, tribology, wear mechanisms, ripple pattern formation.

\section{INTRODUCTION}

Diamond and diamond films have attracted considerable interest in tribological applications due to unique properties of diamond including high hardness and Young's modulus, low coefficient of friction (COF) and high chemical inertness. In the past different wear mechanisms of the diamond films were investigated. Wear on diamond is a load- and velocity-dependent process [1]. Surface morphology [2], diamond grain orientation [3], formation of an amorphous carbonaceous lubricating layer [1] and passivation of dangling carbon bonds by species from ambient environment [4] play a significant role in understanding of the frictional behavior of diamond films.

The formation of transversal ripples and longitudinal grooves on the wear scars surface on NCD films were reported in our previous studies $[5,6]$. It is a complex phenomenon and therefore can not be explained by a single mechanism [6]. For instance, it was found that the morphological changes in ripple patterns depend on the ball material [6] and test duration [5].

The present study aims to investigate the underlying mechanisms of NCD film deflection and ripples formation during sliding against $\mathrm{Si}_{3} \mathrm{~N}_{4}$ balls.

\section{EXPERIMENTAL DETAILS}

A $0.8 \mu \mathrm{m}$ thick NCD film was grown on a $100 \mathrm{~mm}$ diameter (100)-oriented $500 \mu \mathrm{m}$ thick Si wafer by hotfilament chemical vapour deposition (HFCVD) using an

\footnotetext{
* Corresponding author. Tel.: +372-56506423.

E-mail address: andrei.bogatov@ttu.ee (A.Bogatov)
}

sp3 Diamond Technologies, Inc. 655 reactor in a $2.4 \%$ $\mathrm{CH}_{4} / \mathrm{H}_{2}$ gas mixture. The substrate temperature was about $850{ }^{\circ} \mathrm{C}$ and the chamber pressure was maintained at 6 Torr ( $800 \mathrm{~Pa})$. After the NCD film deposition, the Si wafer was cut into bars of about $10 \mathrm{~mm}^{2}$ in size along cleavage directions.

Room temperature Raman spectra were recorded by using a Horiba LabRam HR 800 high-resolution spectrometer equipped with a multichannel CCD detection system in the backscattering configuration. The laser light wavelength was $532 \mathrm{~nm}$, and the spectral resolution of the spectrometer was $0.5 \mathrm{~cm}^{-1}$.

Reciprocating sliding tests (normal load $2 \mathrm{~N}$, displacement amplitude $1 \mathrm{~mm}$, frequency 2, 5 and $8 \mathrm{~Hz}$, relative humidity about $35 \%$, ball diameter $\varnothing 3 \mathrm{~mm}$ ) were carried out by means of a CETR ${ }^{\circledR}$ UMT-2 tribometer. $\mathrm{Si}_{3} \mathrm{~N}_{4}$ balls (surface roughness $\mathrm{R}_{\mathrm{a}}=0.012 \mu \mathrm{m}$ ) (REDHILL, Czech Republic) were used as a counter body. The duration of the tests was 1800, 3000 and 6000 cycles.

According to producer provided data, the hardness, Young's modulus and Poisson ratio of the $\mathrm{Si}_{3} \mathrm{~N}_{4}$ balls were 1400-1700 HV, $310 \mathrm{GPa}$ and 0.27, respectively. Monocrystalline Si (100) possesses a hardness of about 12 GPa [7]; due to crystal anisotropy its Young's modulus varies along the (100) plane from about 130 [8] to $170-$ $180 \mathrm{GPa}[7,8]$, the Poisson ratio is 0.278 [9], the fracture strength measured on Si (100) wafers is about $6.1 \mathrm{GPa}$ [10]. In the context of the present study, a dependence of mechanical properties of the $\mathrm{Si}$ single crystal on the temperature should be considered. The brittle-to-ductile transition (BDT) occurs in Si at about $530^{\circ} \mathrm{C}$ [11-13]. Brittle rupture (brittle plasticity) of monocrystalline $\mathrm{Si}$ 
takes place at a temperature of $<530{ }^{\circ} \mathrm{C}$ and at higher temperature the formation and movement of dislocations results in ductile plasticity.

AFM measurements (NT-MDT Solver P47H) were performed in contact mode using Si cantilevers and tips. Profilometric scans were done with a Mahr Perthometer ${ }^{\circledR}$ (Göttingen, Germany).

\section{RESULTS AND DISCUSSION}

Fig. 1 shows an AFM image taken on the as-deposited NCD film surface. The diamond grains with sharp edges cover the entire Si wafer surface. The maximum grain size is about $0.5 \mu \mathrm{m}$.

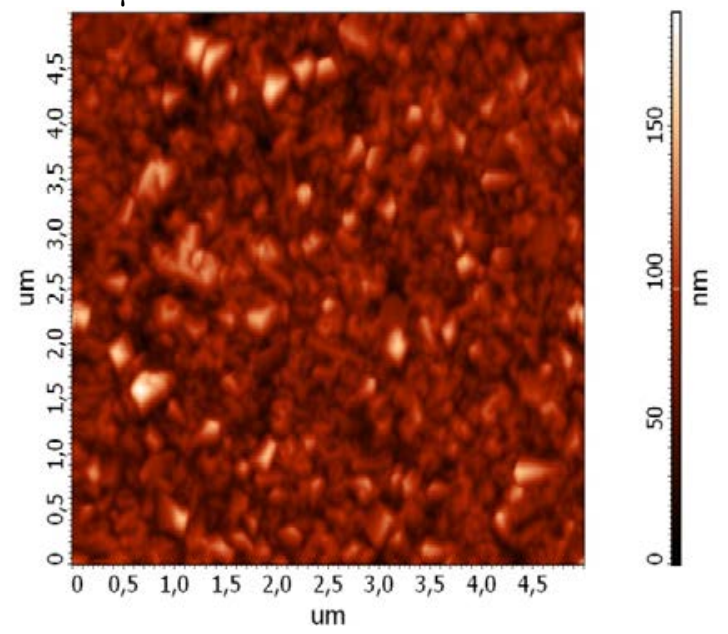

Fig. 1. AFM image of the pristine NCD film surface

Fig. 2 shows the typical Raman spectrum of the NCD film. The peaks at 522 and $976 \mathrm{~cm}^{-1}$ correspond to the Si substrate, the peak at $1332 \mathrm{~cm}^{-1}$ relates to diamond and the peaks at 1134 and $1478 \mathrm{~cm}^{-1}$ are ascribed to the presence of trans-polyacetylene (t-PA) at the grain boundaries [14]. The peaks at 1355 and $1540 \mathrm{~cm}^{-1}$ correspond to the $\mathrm{D}$ and G bands [15].

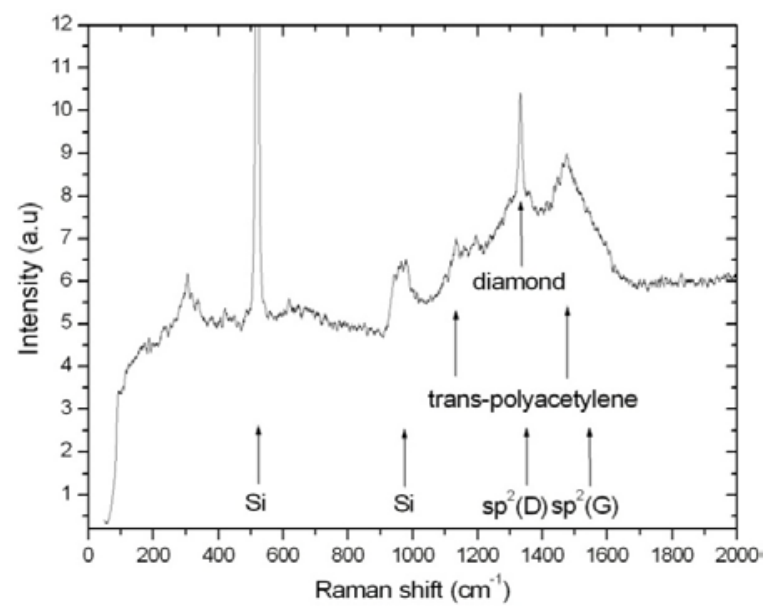

Fig. 2. Raman spectrum of the pristine NCD film

Fig. 3 shows the coefficient of friction (COF) versus number of cycles curves for 6000 cycles of sliding for the used test frequency of 2, 5 and $8 \mathrm{~Hz}$ respectively. The highest COF value is observed at the beginning of the tests and is related to the high NCD film surface roughness. Because of the progressing NCD film surface abrasion, the COF value decreases gradually and, finally, stabilizes at about 0.1 . In the case of the test done at $8 \mathrm{~Hz}$, the run-in period is shorter than for tests carried out at 2 and $5 \mathrm{~Hz}$, i.e. the surface smoothening proceeds faster with the higher ball velocity.

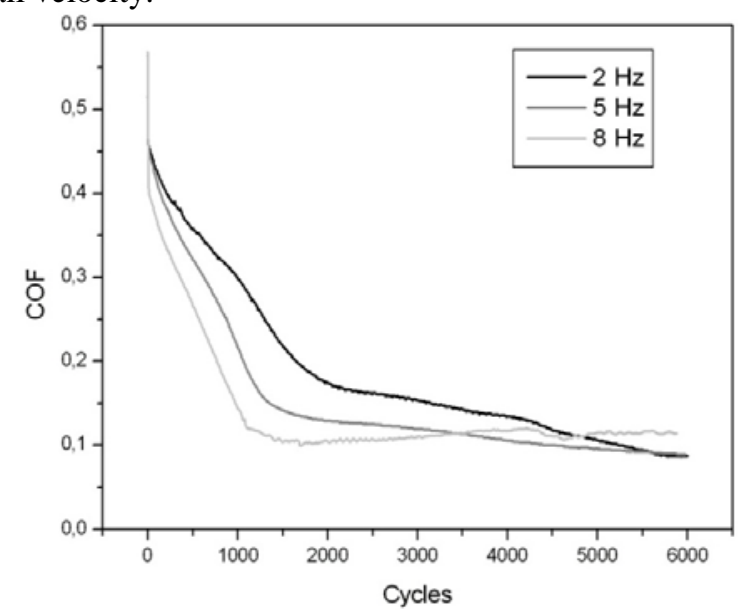

Fig. 3. COF versus cycle curves after 6000 cycles of sliding at 2, 5 and $8 \mathrm{~Hz}$

Fig. 4 shows an AFM image taken on the central region of the wear scar after 1800 cycles sliding at $8 \mathrm{~Hz}$.

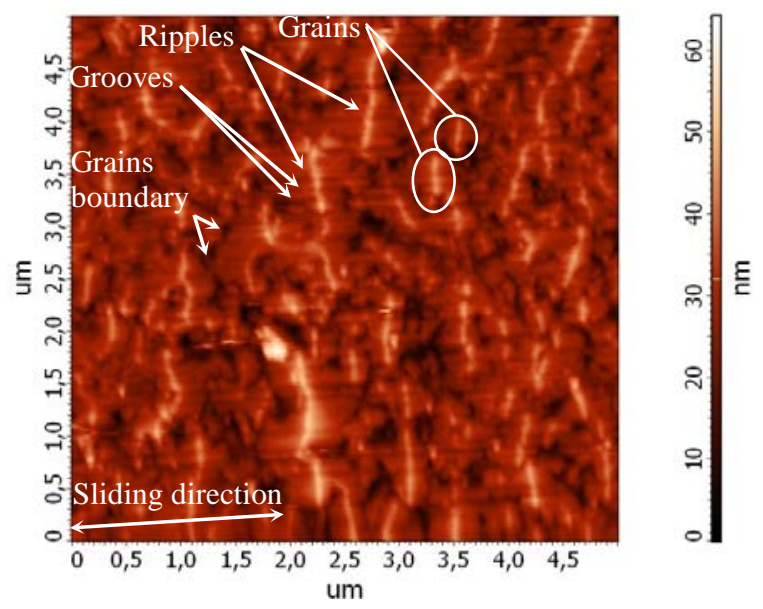

Fig. 4. AFM image of the worn NCD film surface after 1800 cycles of sliding at $8 \mathrm{~Hz}$

A polished surface on top of diamond grains can be observed and clear ripple patterns are formed approximately at the middle of diamond grains (visible as white lines in the AFM image). Line scans taken on the wear scars by means of mechanical profilometry are shown in Fig. 5. The roughness of the NCD film as measured by AFM decreases from the average roughness value $R_{\mathrm{a}}=0.019 \mu \mathrm{m}$ (ten point height of irregularities value $\left.R_{\mathrm{z}}=0.105 \mu \mathrm{m}\right)$ for the as-deposited NCD film surface to $R_{\mathrm{a}}=0.005 \mu \mathrm{m}\left(R_{\mathrm{z}}=0.032 \mu \mathrm{m}\right)$ for the wear scar surface after 1800 cycles of sliding at $8 \mathrm{~Hz}$, see Fig. 6 a. In other words, the parameter $\mathrm{R}_{\mathrm{z}}$ is an average distance between the highest peaks and deepest valleys. A level of the border of the most low-lying valleys is schematically indicated by the dashed line in Fig. $5 \mathrm{c}$ and Fig. 6. At the beginning of the sliding, wear takes place on the NCD film surface corrugations. After 1800 cycles of sliding at $8 \mathrm{~Hz}$, grain boundaries can clearly be observed in Fig. 4. Therefore, it can be expected that the level of the border of the wear scar bed should lie above the level of the border of the most low-lying valleys of unaffected as-deposited NCD film surface. However, the level of the border of the wear 


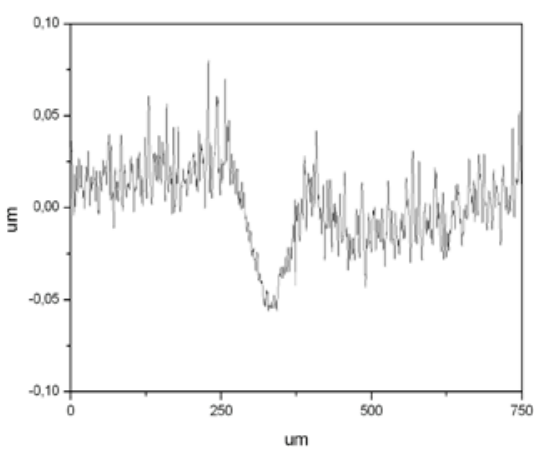

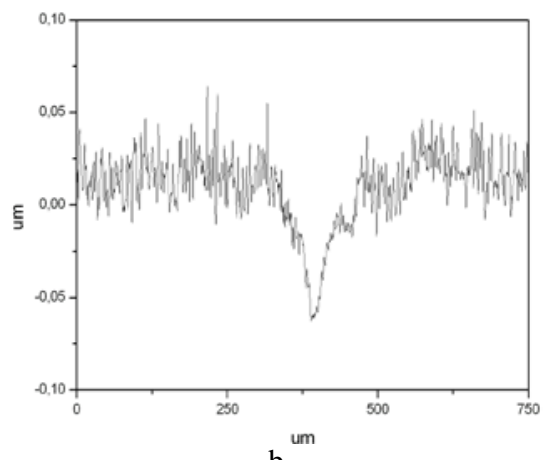

b

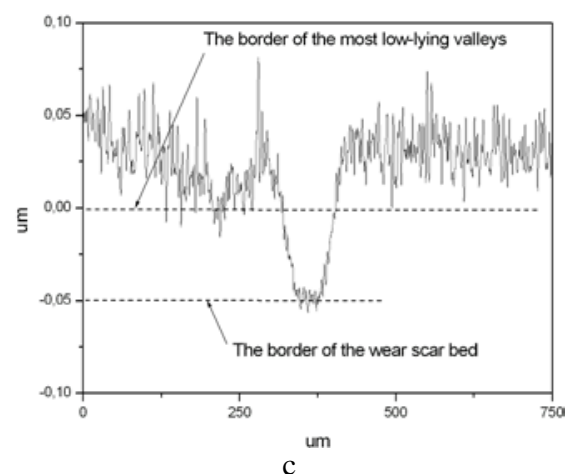

Fig. 5. Line scans taken on the wear scars after 1800 cycles of sliding at $2 \mathrm{~Hz}$ (a), $5 \mathrm{~Hz}$ (b) and $8 \mathrm{~Hz}$ (c)

scar bed lies well below the level of the border of the most low-lying valleys of the pristine NCD film surface, see Fig. 5 c. Schematically, these results are represented in Fig. 6 a. The results of profilometric measurements shown in Fig. $5 \mathrm{c}$ are more adequately described by the scheme shown in Fig. 6 a than in Fig. 6 b by recognizing that the grain boundaries can be seen in Fig. 4. Indeed, it is assumed that the NCD film is not deflected at the scheme shown in Fig. 6 b, however the analysis of wear scars profile suggests that the NCD film can be plastically deformed during the sliding tests. This vertical deformation (further called ,deflection') is about $0.05 \mu \mathrm{m}$ after 1800 cycles sliding at $8 \mathrm{~Hz}$, wherein, no visible cracks were observed on the wear scars surface. Note that a similar NCD film deflection was observed after 3000 and 6000 cycles of tribotests (not shown) as well.

The contact pressure of the Si (100) clean surface in contact with a $\mathrm{Si}_{3} \mathrm{~N}_{4}$ ball can be estimated based on Hertzian contact mechanics. It is about $0.8-0.9 \mathrm{GPa}$ under a load of $2 \mathrm{~N}$. Due to the high hardness and fracture strength of silicon, it is unlikely that under such a contact pressure Si (100) undergoes a brittle fracture at room temperature.

In this case of a hard coating on a soft substrate the coating thickness and hardness and the Young's modulus of both coating and substrate are the principal parameters affecting the tribological behavior of the coating/substrate system [16]. Thin layers subjected to contact with the counterpart only partially carry the stress distribution, the rest of the stress is carried by the substrate, see Fig. 6 a. In the case of the NCD film on top of Si (100) wafer, the calculation of contact pressure becomes more complicated due to the roughness of the diamond film (see Fig. 1).

Based on our experimental observations, we believe that the NCD film deformation can be explained by the plastic deformation of the Si (100) substrate. Firstly, the formation of a dislocation network on the $\mathrm{Si}$ (100)/diamond film interface was found after the deposition of diamond film at $690^{\circ} \mathrm{C}$ [17]. Note that the NCD film deposition temperature was $850^{\circ} \mathrm{C}$ in the present study, i.e. well above the BDT temperature in $\mathrm{Si}$ $\left(>530{ }^{\circ} \mathrm{C}\right.$ ) Therefore, an induced plastic deformation of the Si wafer can already be expected after the NCD film deposition. Secondly, the actual value of the contact pressure on the Si wafer can be remarkably higher than the calculated value mentioned above. Indeed, at the beginning of the test the $\mathrm{Si}_{3} \mathrm{~N}_{4}$ ball is placed in contact with the apex of sharp diamond grains. Therefore, the local contact pressure between a particular grain and the $\mathrm{Si}_{3} \mathrm{~N}_{4}$ ball surface can be greatly underestimated from the aforementioned calculation for the ball on the plain surface.

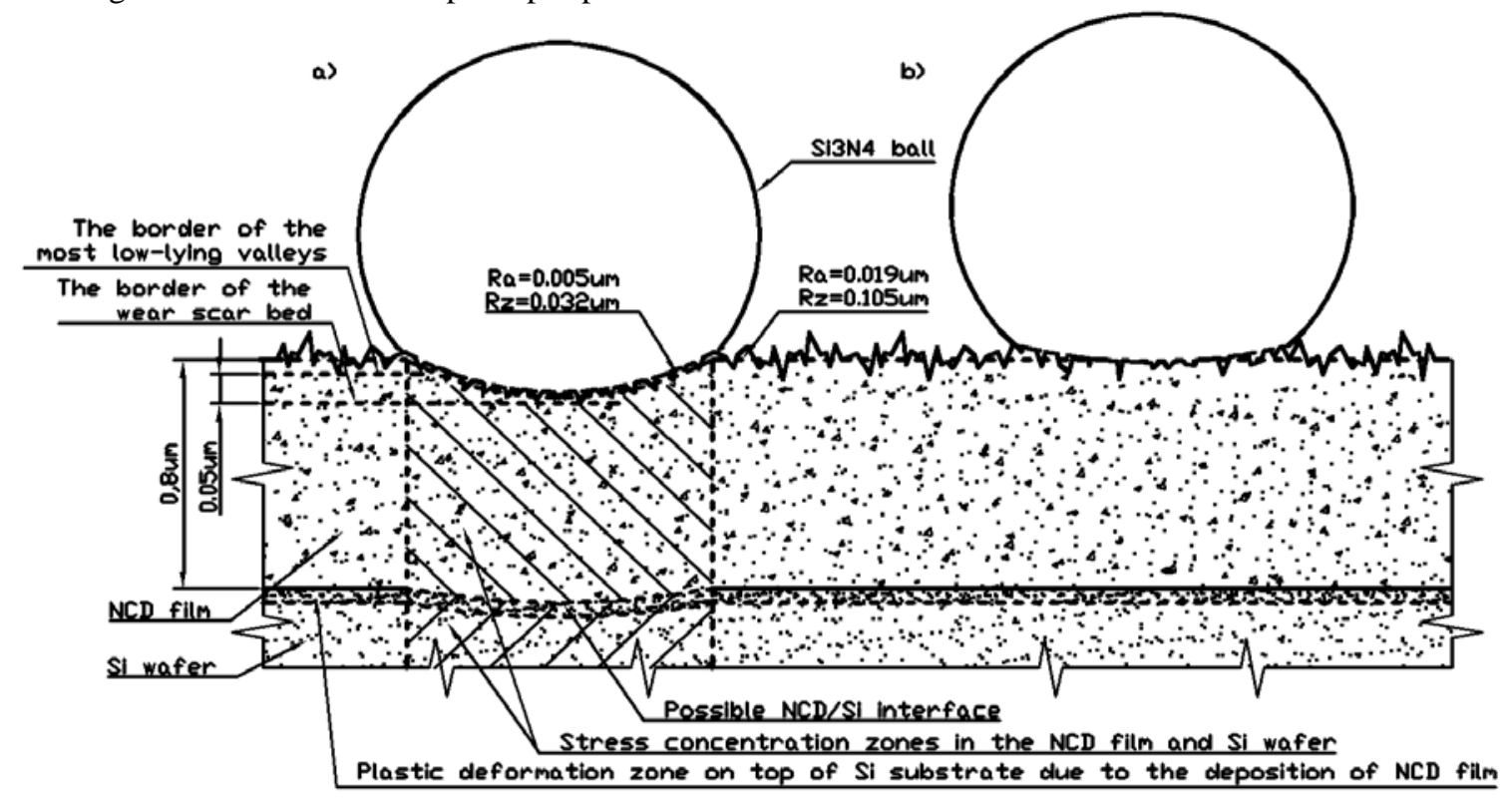

Fig. 6. Schematic representation of the results shown in Fig. 5 c: wear scar profile according to profilometric measurements after 1800 cycles sliding at $8 \mathrm{~Hz}$ (a) and expected wear scar profile in assumption that no NCD film deflection occurs (b) 
This high local contact pressure could induce the deformation of the Si wafer surface. Thirdly, a high local temperature at the so-called frictional hot-spots $[18,19]$, i.e. at points of contact between surface asperities of the counterbodies, can account for the Si wafer mechanical properties variation. In conclusion, the BDT effect in Si at high NCD film deposition temperature and high local contact pressure and temperature during sliding can lead to the plastic deformation of Si surface on the Si(100)/NCD interface. Thus, the NCD film deformation could occur as a consequence of the $\mathrm{Si}$ substrate plastic deformation. However, likely due to the high Young's modulus and fracture strength of the NCD film no cracks on the NCD film surface were found. It is worth noting that the aforementioned high local contact pressure and temperature during sliding are considered in conjunction with the graphitization of diamond and diamond films $[1,6,18,19$ and references therein], without the possible influence on the global deformation of diamond films.

The high Young's modulus and a relatively small thickness of the NCD film provide flexibility to the NCD film [16] and hence the NCD film surface can follow the surface deformation during sliding without cracks and surface failure. A bent torus on the NCD film surface is likely formed in front of the ball as shown in [16] during sliding. In addition, the torus size can be affected due to the plastic deformation on the $\mathrm{Si}(100) / \mathrm{NCD}$ film interface. Periodic bending of the NCD film during reciprocating sliding could contribute to the formation of transversal protrusions on top of NCD film, i.e. surface ripples.

\section{CONCLUSIONS}

We observed the deformation of NCD films after sliding tests. The BDT effect in Si, high local contact pressure and temperature during sliding induce a plastic deformation on the Si single crystal surface, which leads to the deflection of the NCD film during reciprocal sliding. On the other hand the periodic bending of the NCD film during sliding can be considered as an extra factor affecting the formation of ripple patterns on the wear scars surface.

\section{Acknowledgment}

This work was supported by institutional research funding IUT-19-29 of the Estonian Ministry of Education and Research.

\section{REFERENCES}

1. Pastewka, L., $\quad$ Moser, S., $\quad$ Gumbsch, P., $\quad$ Moseler, M. Anisotropic Mechanical Amorphization Drives Wear in Diamond Nature Materials 10 2011: pp. 34-38.

2. Bhushan, B., Subramaniam, V. V., Malshe, A., Gupta, B. K., Ruan, J. Tribological Properties of Polished Diamond Films Journal of Applied Physics 74 (6) 1993: pp. 4174-4180.

3. El-Dasher, B. S., Gray, J. J., Tringe, J. W., Biener, J., Hamza, A. V. Crystallographic Anisotropy of Wear on a Polycrystalline Diamond Surface Applied Physics Letters 88 2006: pp. 241915-1-3.

4. Konicek, A. R., Grierson, D. S., $\quad$ Sumant, A. V., Friedmann, T. A., $\quad$ Sullivan, J. P., $\quad$ Gilbert, P. U. P. A., Sawyer, W. G., Carpick, R. W. Influence of Surface Passivation on the Friction and Wear Behavior of Ultrananocrystalline Diamond and Tetrahedral
Amorphous Carbon Thin Films Physical Review B 85 2012: pp. 155448-1-13.

5. Bogatov, A., $\quad$ Podgursky, V., $\quad$ Raadik, T., $\quad$ Kamjula, A. R., Hantschel, T., Tsigkourakos, M., Kulu, P. Investigation of Morphology Changes on Nanocrystalline Diamond Film Surfaces during Reciprocating Sliding against $\mathrm{Si}_{3} \mathrm{~N}_{4}$ Balls Key Engineering Materials 604 2014: pp. 126-129. http://dx.doi.org/10.4028/www.scientific.net/KEM.604.126

6. Podgursky, V., Hantschel, T., Bogatov, A., Kimmari, E., Antonov, M., Viljus, M., Mikli, V., Tsigkourakos, M., Vandervorst, W., Buijnsters, J. G., Raadik, A. T., Kulu, P. Rippling on Wear Scar Surfaces of Nanocrystalline Diamond Films after Reciprocating Sliding against Ceramic Balls Tribology Letters 55 2014: pp. 493-503. http://dx.doi.org/10.1007/s11249-014-0379-z

7. Bhushan, B., Li, $\mathbf{X}$. Micromechanical and Tribological Characterization of Doped Single-Crystal Silicon and Polysilicon Films for Microelectromechanical Systems Devices Journal of Materials Research 12 (01) 1997: pp. 54-63.

8. Boyd, E. J., Uttamchandani, D. Measurement of the Anisotropy of Young's Modulus in Single-Crystal Silicon Journal of Microelectromechanical Systems 21 (1) 2012: pp. 243-249.

http://dx.doi.org/10.1109/JMEMS.2011.2174415

9. Gan, L., Ben-Nissan, B., Ben-David, A. Modelling and Finite Element Analysis of Ultra-Microhardness Indentation of Thin Films Thin Solid Films 290-291 1996: pp. 362-366.

10. Ericson, F., Schweitz, J. A. Micromechanical Fracture Strength of Silicon Journal of Applied Physics 68 1990: pp. 5840 5844

11. John, C. S. The Brittle-to-Ductile Transition in Pre-Cleaved Silicon Single Crystals Philosophical Magazine 32 1975: pp. 1193 -1212. http://dx.doi.org/10.1080/14786437508228099

12. Sen, D., Thaulow, C., Schieffer, S. V., Cohen, A., Buehler M. J. Atomistic Study of Crack-Tip Cleavage to Dislocation Emission Transition in Silicon Single Crystals Physical Review Letters 104 2010: pp. 235502-1-4.

13. Sen, D., Cohen, A., Thompson, A. P., Duin, A. V., Goddard III, W. A., Buehler, M. J. Direct Atomistic Simulation of Brittle-to-Ductile Transition in Silicon Single Crystals Materials Research Society Proceedings 1272 2010: pp. 1272-04-13.

14. Ferrari, A. C., Robertson, J. Raman Spectroscopy of Amorphous, Nanostructured, Diamond-Like Carbon, and Nanodiamond Philosophical Transactions of the Royal Society A 362 2004: pp. 2477-2512.

15. Ferrari, A. C., Robertson, J. Resonant Raman Spectroscopy of Disordered, Amorphous, and Diamondlike Carbon Physical Review B 64 2001: pp. 075414-1-13.

16. Holmberg, K., Laukkanen, A., Ronkainen, H., Wallin, K., Varjus, S., Koskinen, J. Tribological Contact Analysis of a Rigid Ball Sliding on a Hard Coated Surface Part II: Material Deformations, Influence of Coating Thickness and Young's Modulus Surface and Coating Technologies 200 2006: pp. 3810-3823.

17. Michler, J., Mermoux, M., von Kaenel, Y., Haouni, A., Lucazeau, G., Blank, E. Residual Stress in Diamond Films: Origins and Modelling Thin Solid Films $357(2)$ 1999: pp. 189-201. http://dx.doi.org/10.1016/S0040-6090(99)00528-3

18. Bowden, F. P., Freitag, E. H. The Friction of Solids at Very High Speeds Proceedings of the Royal Society A 248 1958: pp. 350-367.

19. Erdemir, A., $\quad$ Halter, M., $\quad$ Fenske, G. R., $\quad$ Zuiker, C., Csencsits, R., Krauss, A. R., Gruen, D. M. Friction and Wear Mechanisms of Smooth Diamond Films during Sliding in Air and Dry Nitrogen Tribology Transactions 40 1997: pp. 667-675. 